\title{
TAFSIR TARBAWI
}

\author{
Badruzzaman M. Yunus \\ Dosen Fakultas Ushuluddin UIN Sunan Gunung Djati Bandung \\ Jl. A.H. Nasution 105 Cibiru Bandung 40614, Indonesia. \\ E-mail: badr.yunus@yahoo.com
}

\begin{abstract}
Tafsir of education (tafsir tarbawī) emerges to accommodate academic need to develop local and national curriculum at Islamic higher education. Its aims is to enrich Islamic education faculty to prepare educators an Islamic perspective of education based on Alquran and Hadis. However, this kind of tafsir yet to become an independent study but merely an approach or a model created to accommodate the need on specific dicipline of study.The reason for this is because tafsir of education still need perfection in its concept compared to already established tafsir like tafsïr ahkām (tafsir of legal issues).
\end{abstract}

Keywords:

Tafsir tarbawi; education; curriculum; academic; approach; method.

\begin{abstract}
Abstrak
Tafsir pendidikan atau tafsir tarbawi lahir untuk memenuhi kebutuhan akademik dalam rangka pengayaan kurikulum lokal atau kurikulum Nasional di PTAI, dengan harapan bahwa jurusan tarbiyah diharapkan mampu mempersiapkan calon pendidik dalam wilayah pendidikan Islam. Oleh karena itu, agar pendidikan Islam mampu mewarnai profesi yang disandang oleh pendidik secara professional, yaitu menuju pendidikan Islami yang mampu mengembalikan paradigma pendidikan kepada sumber dasar ajaran Islam yaitu Alquran dan Hadis, maka lahirlah disiplin tafsir sebagai alternatif kajian yang mempunyai relasi dengan pendidikan yang kemudian disebut. Namun persoalan yang kemudian timbul adalah apakah ini dianggap sebagai disiplin ilmu secara mandiri atau hanya merupakan sebuah metode pendekatan atau lebih spesifik lagi merupakan corak atau model penafsiran yang dikondisikan dengan kebutuhan.Tafsir pendidikan belum mempunyai perangkat, metode dan pendekatan yang proporsional, sebagaimana layaknya sebuah disiplin ilmu tafsir. Istilah tafsir pendidikan baru sebagai wacana dan manifestasi ijtihad para akademisi yang peduli dengan pendidikan Islam untuk memenuhi kebutuhan akademik dalam rangka penyempurnaan kurikulum pada perguruan Tinggi. Maka agak sulit rasanya jika memposisikan tafsir pendidikan sebagai bagian dari kajian tafsir yang sudah dianggap mapan, apalagi jika dibandingkan dengan tafsirtafsir lain seperti tafsir ahkām dan lain-lain.
\end{abstract}

Kata Kunci:

Tafsir tarbawī; pendidikan; kurikulum; akademik; pendekatan; metode.

\section{A. PENDAHULUAN}

Alquran adalah kalamullāh yang diturunkan kepada Nabi Muhammad sebagai mukjizat yang ditulis dalam mushaf dan diriwayatkan dengan mutawatir serta membacanya adalah ibadah. Alquran diturunkan tidak hanya kepada manusia tetapi juga jin agar bisa dijadikan petunjuk (hudan) dan pembeda (furqān) antara kebenaran dan kesesatan. ${ }^{1}$

Allah menurunkan Alquran untuk dibaca dengan penuh penghayatan (tadabbur), meyakini kebenarannya dan berusaha untuk mengamalkannya.Allah berfirman,

\footnotetext{
${ }^{1}$ QS. Al-Baqarah,[2]:185.
}

"Maka apakah mereka tidak memperhatikan Alquran?Kalau kiranya Alquran itu bukan dari sisi Allah, tentulah mereka mendapat pertentangan yang banyak di dalamnya. (QS. Al-Nisā,[4]:82).

Juga firman Allah, "Maka apakah mereka tidak memperhatikan Alquran ataukah hati mereka terkunci (QS. Muhammad,[47]:24).

Alquran adalah sumber ajaran Islam yang berhubungan dengan totalitas kehidupan manusia.Dalam kenyataan empirik, tidak dapat dipungkiri, bahwa ketika sumber ajaran itu hendak dihapami dan dikomunikasikan dengan kehidupan manusia yang pluralistik, diperlukan keterlibatan pemikiran yang merupakan kreatifitas manusia. 
Alquran sebagai kitab suci ummat Islam, selalu memberi bimbingan dan mengajak umat manusia untuk mencapai kebajikan dan kesentosaan dalam kehidupan melalui dialog sesuai dengan strata, status dan kemampuan masing-masing. Kesemuanya ikut merasa memiliki dan mengambil bagian dari isi dan petunjuk yang dikandung Alquran sesuai dengan human interest, spesialisasi serta subjektifitas masing-masing, baik awam, cendekiawan, kaya, miskin, berpangkat, rakyat jelata dan lain sebagainya. Alquran selalu berupaya menunjukkan manusia kepada tujuan yang ingin dicapai dalam kehidupan. Oleh karenanya Alquran sering menyifati dirinya sebagai petunjuk ( $h u d \bar{a})$, rahmat, peringatan (al-dzikr), nasehat (mau'izhah) dan lain-lain. ${ }^{2}$

Tidak terlalu asing dalam tataran pemahaman kitab suci Alquran kalau muncul berbagai pendekatan yang dikenal dengan istilah tafsir.Dalam dunia tafsir muncul berbagai terminologi pendekatan dengan berbagai variasi disiplin ilmu yang menghampirinya.Pada abad awal dunia Islam, kehadiran ilmu tafsir merupakan terminologi tunggal dan ideal untuk memaknai Alquranyangberpredikat sebagai proper noun of understanding Alquran (memayungi namanama disiplin keilmuan yang berhubungan dengan Alquran).

Tafsir Tarbawi, yang merupakan ijtihad akademisi tafsir, berupaya mendekati Alquran melalui sudut pandang pendidikan, baik dari segi teoretik maupun praktik. Ijtihad ini diharapkan dapat mewacanakan sebuah paradigma tentang konsep pendidikan yang dilandaskan kepada kitab suci dan mampu untuk diimplementasikan sebagai nilai-nilai dasar dalam pendidikan. ${ }^{3}$

\section{B. HASIL DAN PEMBAHASAN}

\section{Terminologi Tafsir Pendidikan (tarbawī)}

Kata tafsir (تَفَفِيْرْ) adalah bentuk masdar dari kata فَسّرَ (fassara) yang secara etimologis

\footnotetext{
${ }^{2}$ Sayyid Muhammad Husin al-Thaba-Thabā', $\overline{1}$, AlQur'an Fì al-Islām(Beirut: Jam'iyyah al-Tsaqāfiyyah al-Ijtimā'iyyah, 1973), 73.

${ }^{3}$ Ahmad Munir, Tafsir Tarbawi: Mengungkap Pesan Al-Qur'an Tentang Pendidikan, cet. I,(Yogyakarta; Teras; 2008), 8.
}

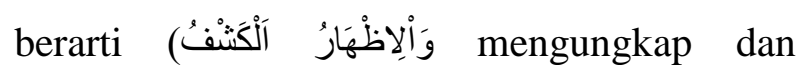
menampakkan). ${ }^{4}$ Kata tafsir juga berarti menerangkan sesuatu yang masih samar serta menyingkap sesuatu yang tertutup. Dalam kaitannya dengan kata, tafsir berarti menjelaskan makna kata yang sulit dipahami sehingga kata tersebut dapat dipahami maknanya. ${ }^{5}$ Dalam pendapat yang lain, kata tafsir ini diambil dari kata tafsiroh yang berarti suatu perkakas yang dipergunakan tabib untuk mengetahui penyakit orang lain. ${ }^{6}$

Dengan demikian, secara etimologis kata tafsir adalah digunakan untuk menunjukkan maksud (menjelaskan, mengungkap, menerangkan) suatu masalah yang masih kabur, samar dan belum jelas.

Berdasarkan pengertian etimologis tersebut dapat dipahami bahwa suatu kata tidak dapat dikatakan telah mengalami proses penafsiran jika tidak terdiri dari kata yang masih samar dan belum jelas maknanya. Jika ada orang yang mendengar suatu ucapan yang memiliki makna zhahir yang secara spontan dapat dipahami kemudian memberitahukan makna dari ucapan tersebut, maka makna yang disampaikannya itu bukanlah penafsiran. Hal itu karena pada hakikatnya ia tidak mengungkapkan atau menjelaskan sesuatu yang sebelumnya masih samar. Sesuatu dapat dikatakan telah mengalami suatu proses penafsiran jika seseorang telah berusaha dan bersungguh-sungguh untuk mengungkap dan menjelaskan ucapan yang masih terlihat samar atau rancu.

Sedangkan kata tarbiyah, secara leksikaltidak ditemukan dalam Alquran.Akan tetapi ditemukan bahwa Alquran mempergunakan kata-kata yang akar katanya mempunyai sumber derivasi (isytiqāq) yang sama dengan al-tarbiyyah. Kata-kata yang dimaksudialah al-rabb, rabbayāni, nurabbī,

\footnotetext{
${ }^{4}$ Muhammad Husein Al-Zahabi, at-Tafsir wa alMufassirūn, Juz I,(Mesir: Dār al-Maktūb al-Haditsah, 1976), 13 .

${ }^{5}$ Tim Penyusun, Ensiklopedia Alquran; Kajian Kosa Kata, Ed. Sahabuddin, (Jakarta: Lentera Hati, 2007), 975.

${ }^{6}$ Teungku Muhammad Hasbi Ash-Shiddiqy dkk., Sejarah dan Pengantar Ilmu Alquran dan Tafsir, (Semarang: PT. Pustaka Rizki Putera, 1999), 172.
} 
ribbīn, rabbāni. Demikian pula, dalam hadis ditemukan penggunaan istilah rabbāni.

Meskipun kelihatannya semua istilah tersebut mempunyai pola akar kata yang sama, namun masing-masingmempunyai konotasi makna yang berbeda-beda.

Apabila istilah al-tarbiyyah dilacak maknanya dari kata $a l-r a b b$, maka ditemukan berbagai konotasi makna yang diketengahkan oleh para pakar bahasa sebagai berikut :

a. Louis Ma'luf mengartikan al-Rabb dengan tuan, pemilik, memperbaiki, perawatan, tambah, mengumpulkan, dan memperindah. $^{7}$

b. Abì Abdillāh Muhammadbin Ahmad alAnbāri al-Qurthūbi memberikan arti alrabb dengan pemilik, tuan, Yang Maha Memperbaiki, Yang Maha Pengatur, Yang Maha Menambah, dan Yang Maha Menunaikan. ${ }^{8}$ Pengertian di atas merupakan interpretasi dari kata $a l-r a b b$ dalam surah al-Fätihah, yang merupakan nama dari nama-nama Allah Swt.

c. Imam Fakhruddin al-Rāzi berpendapat bahwa $a l-r a b b$ merupakan kata yang seakar dengan al-tarbiyyah yang mempunyai makna al-tanmiyyah (pertumbuhan dan perkembangan). ${ }^{9}$

d. Al-Jauharari memberikan makna altarbiyyah, rabbān dan rabba, adalah: Memberi makan, memelihara, dan mengasuh. ${ }^{10}$

Sedangkan secara terminologi, para ahli memiliki cara yang beragam dalam memberikan makna al-tarbiyyah. Hal itu dapat dilihat sebagai berikut:

${ }^{7}$ Louis Ma'luf, al-Munjid fí al-Lughah wa al-A'lām, Cet. XXVII,(; Beirut: Dār al- Masyriq, 1984),243-244.

${ }^{8}$ Abí Abdillāh Muhammad bin Ahmad al-An‘ārí alQurthubí, al-Jāmi' li-Ahkāmi al-Qur'ān,Jilid I (t.t), 136137.

${ }^{9}$ Imām Fakhruddín al-Rāzi, Tafsìr al-Kabīr, Jilid X. Juz XX,Cet. I, (Beirut: Dār al-Kutub al-'Ilmiyah, 1990), 153

${ }^{10}$ Syed Muhammad al-Naquib Al-Attas, The Concept of Education in Islam: A Frame Work for an Islamic Philosophy of Education. Diterjemahkan oleh Haidar Baqir dengan judul “ Konsep Pendidikan Dalam Islam: Suatu Rangka Pikir Pembinaan Filsafat Pendidikan Islam",Cet. I,(Bandung: Mizan, 1984),66. a. Muhammad Jamaluddin al-Qāsimi berpendapat bahwa al-tarbiyyah ialah proses penyampaian sesuatu sampai pada bataskesempurnaan yang dilakukan secara tahap demi tahap. ${ }^{11}$ Pendapat senada dikemukakan oleh alAshfahāniyangmenyatakan bahwa pengertian tarbiyyah adalah proses menumbuhkan secara bertahap yang dilakukan secara bertahap sampai pada batas kesempurnaan. ${ }^{12}$

b. Abdul Fattāh Jalāl mendefinisikan istilah al-tarbiyyahsebagaiproses persiapan dan pemeliharaan anak pada masa kanak-kanak di dalam keluarga. ${ }^{13}$ http://ibrah78bahasaarab.blogsp ot.com/2010/03/tafsir-tarbawi.html - ftn13

c. Ismāil Haqi al-Barusāwì berpendapat bahwa al-tarbiyyah bermakna proses pemberian nafsu dengan berbagai kenikmatan, pemeliharaan hati nurani dengan berbagai kasih sayang, bimbingan jiwa dengan hukum-hukum syari'ah, serta pengarahan hati nurani dengan berbagai etika kehidupan dan penerangan rahasia hati dengan hakikat pelita. ${ }^{14}$

d. Mustafā al-Ghulāyaini berpendapat bahwa al-tarbiyyahadalah penanaman etika yang mulia pada jiwa anak yang sedang tumbuh dengan cara memberi petunjuk dan nasihat,

\footnotetext{
${ }^{11}$ Muhammad Jamāluddin al-Qāsimí, Tafsir Mahāsin al-Ta'wỉl,Cet. II,(Beirut: Dār al- Fikr, 1978), 8.

${ }^{12}$ Abdurrahmān al-Nahlāwí, Ushūl al-Tarbiyyah alIslāmiyyah wa Asālibihā fỉ al-Baiti wa Madrāsati wal Mujtama', Cet. I, (Beirut; Dār al-Fikr, 1979), 13.

${ }^{13}$ Abdul Fattāh Jalāl, Min al-Ushūl al-Tarbawiyah fí al-Islām,diterjemahkan oleh Herry Noer Ali dengan judul Asas-Asas Pendidikan IslamCet.I, (Bandung: CV.Dipenogoro, 1988), 28.Pengertian-pengertian tersebut di atas, digali dari maksud QS. al-Isrā'[17]:24 dan QS. al-Syu' arā'[26]:18. Objek kedua ayat tersebut diperuntukkan bagi bayi dan fase kanak-kanak.

${ }^{14}$ Ismāil Hāqi Al-Barusāwi, Tafsỉr Rūhul al-Bayān, Jilid I, Juz I (Beirut: Dār al-Fikr, t.th),2.Pengertian tersebut khusus diperuntukkan bagi manusia yang mempunyai potensi rohani, sedangkan pengertian altarbiyyah yang dikaitkan dengan alam raya, mempunyai arti pemeliharaan dan memenuhi segala yang dibutuhkan, serta menjaga sebab-sebab eksistensinya.
} 
sehingga ia memiliki potensi-potensi dan kompetensi-kompetensi jiwa yang mantap, yang dapat membuahkan sifat-sifat bijak, baik, cinta akan kreasi, dan berguna bagi tanah airnya. ${ }^{15}$

e. Ahmad Musthafa Al-Maragi memberikan definisi al-tarbiyyahdengan membaginya kepada dua kategori: 1) Tarbiyyah Khalqiyyah, yaitu pembinaan dan pengembangan jasad, jiwa dan akal dengan berbagai petunjuk; 2) Tarbiyyah Diniyyah Tahqibiyyah, yaitu pembinaan jiwa dengan wahyu untuk kesempurnaan akal dan kesucian jiwa. ${ }^{16}$

f. Muhammad Athiyah Al-Abrasyi berpendapat bahwa al-tarbiyyahadalah : Upaya mempersiapkan individu untuk kehidupan yang lebih sempurna, kebahagiaan hidup, cinta tanah air, kekuatan raga, kesempurnaan etika, sistematik dalam berpikir, tajam berperasaan, giat dalam berkreasi, toleransi pada yang lain, berkompetensi dalam mengungkapkan bahasa tulis dan bahasa lisan, serta terampil berkreativitas. ${ }^{17}$

Berdasarkan makna kata tafsir dan tarbiyah tersebut, maka istilah tafsir pendidikan (tafsir tarbawi) dapat diartikan sebagai tafsir yang menitikberatkan pada masalah tarbiyah dalam rangka membangun peradaban yang sesuai dengan petunjuk dan spirit Alquran. Iamerupakan proper dan abstract noun dari term tafs $\bar{i}$, yang termasuk kategori disiplin keilmuan yang baru. Tetapi menempati posisi yang strategis, karena dijadikan sebagai wadah kajian akademik dalam institusi perguruan tinggi, seperti IAIN,

\footnotetext{
${ }^{15}$ Mustafa Al-Ghulāyaini, Iß̧atun Nāsyi,ỉn (Cet.VI; Beirut Maktabah 'Ariyah,1949),185

${ }^{16}$ Ahmad Mustafa Al-Marāghi, Tafsỉr al-Marāghī, Jilid I ( Cet.IV; Mesir: Mu‘āfa al-Bāb alHalaby,1969),30. Dari kedua pengertian tersebut, dapat disimpulkan bahwa al-tarbiyyah adalah proses pembinaan dan pengembangan potensi manusia melalui pemberian berbagai petunjuk, sehingga menyebabkan potensi yang dimiliki manusia dapat tumbuh dengan produktif dan kreatif tanpa menghilangkan etika Ilahi yang telah ditetapkan dalam wahyu-Nya.

${ }^{17}$ Muhammad 'Āiyah Al-Abrasyi, Rūh al-Tarbiyyah wa al-Ta'Tim, (Saudi 'Arabiah : Dār al- Ahyā', t.t.), 7.
}

STAIN, PTAI, dan lain sebagainya, khususnya fakultas atau jurusan Tarbiyah.

Hemat penulis masih terlalu dini untuk memposisikan tafsir pendidikan sebagai bagian dari kajian tafsir yang sudah dianggap mapan, apalagi jika dibandingkan dengan tafsir-tafsir lain seperti tafsìr ahkäm dan lainlain.Hal ini karena tafsir pendidikan belum mempunyai perangkat, metode dan pendekatan yang proporsional sebagaimana layaknya sebuah disiplin ilmu tafsir.Istilah tafsir pendidikan baru sebagai wacana dan manivestasi ijtihad para akademisi yang peduli dengan pendidikan Islam untuk memenuhi kebutuhan akademik dalam rangka penyempurnaan kurikulum pada perguruan Tinggi.

Kedinian terminologi tafsir tarbawi yang diposisikan sebagai tafsir akan terlihat ketika materi yang disajikan oleh para akademisi tafsir sebagaimana yang ada dalam kurikulum. Antara ayat yang dicangkok, dengan topik yang direncanakan, masih banyak yang tumpang tindih. Kerancuan tersebut menimbulkan kebingungan dan kejanggalan secara metodologis. Oleh karena itu, klaim kedinian ini penulis utarakan karena masih banyak hal yang masih belum kongkrit yang memerlukan pembenahan sehingga terminologi tafsir tarbawi ini layak disebut sebagai disiplin ilmu tafsir yang dipersembahkan sebagai salah satu materi kurikulum pada perguruan tinggi.

Di antara masalah yang perlu mendapatkan perhatian dalam terminologi ini adalah, apakah ini dianggap sebagai disiplin ilmu secara mandiri atau hanya merupakan sebuah metode pendekatan atau lebih spesifik lagi merupakan corak atau model penafsiran yang dikondisikan dengan kebutuhan.

Sesuai dengan latar belakang munculnya, terminologi tafsir pendidikan hanya untuk memenuhi kebutuhan akademik dalam rangka pengayaan kurikulum lokal atau kurikulum Nasional di PTAI. Dengan harapan bahwa jurusan tarbiyah mampu mempersiapkan calon pendidik dalam wilayah pendidikan Islam. Oleh karena itu, agar pendidikan Islam mampu mewarnai profesi yang disandang oleh 
pendidik secara profesional yaitu menuju pendidikan yang Islami yang mampu mengembalikan paradigma pendidikan kepada sumber dasar ajaran Islam yaitu Alquran dan al-Hadis, maka lahirlah disiplin tafsir sebagai alternatif kajian yang mempunyai relasi dengan pendidikan yang kemudian disebut tafsir tarbawi.

Tafsir tarbawi yang merupakan ijtihad akademisi di bidang tafsir, berupaya mendekati Alquran melalui sudut pandang pendidikan.Baik dari segi teoretik maupun praktik, sehingga diharapkan paradigma pendidikan dapat dilandaskan kepada kitab suci, dan petunjuk kitab suci mampu diimplementasikan sebagai dasar pendidikan. Tafsir dalam wacana keilmuan sebenarnya tidak jauh berbeda dengan disiplin ilmu lainnya. Hanya saja sebagian masyarakat masih memberikan perhatian yang lebih dibanding dengan yang lain. Sehingga upaya dan terobosan penyegaran pemahaman kitab suci, kadang-kadang justeru difahami sebuah pendangkalan.Kondisi ini kalau dicermati wajar, karena dalam pembagian corak tafsirpun dibedakan antara tafsir bi al-ma'tsür dan tafsir bi al-ra'yi.Tafsir bi al-ma'tsūr dianggap tafsir yang paling autentik, sementaratafsir bi al-ra'yi dianggap masih membawa banyak masalah yang harus diselesaikan.

Dengan demikian upaya pemahaman Alquran yang diyakini keuniversalannya telah memunculkan berbagai terminologi yang berkaitan dengan pemahaman Alquran. Hadirnya terminology Tafsīr Tarbawi dalam hal ini merupakan sebuah metode pemahaman kitab suci (tafsir) yang dilihat dari sisi pendidikan dengan lebih memperhatikan corak pendidikan dalam memberikan analisisnya. ${ }^{18}$

\section{Relasi Tafsir dan Pendidikan}

Tarbiyyah merupakan satu dari sekian cabang tugas kekhalifahan manusia di muka bumi seperti diungkap dalam Alquran. Pada awalnya, tarbiyyah dalam pengertian pengajaran ('allama) merupakan proses

\footnotetext{
${ }^{18}$ Ahmad Munir, Tafsir Tarbawi: Mengungkap Pesan Al-Qur'an Tentang Pendidikan,8.
}

transfering sifat-sifat Allah kepada hambaNya, Adam. Manusia diunggulkan Allah atas mahluk-Nya yang lain karena pada Adam terdapat proses pengajaran sehingga ia diamanahkan untuk memakmurkan bumi ini. Melalui proses pengajaran, potensi manusia dioptimalkan agar mengerti cara berinteraksi dengan kehidupan dunia dan bersikap yang benar terhadapnya. Pengajaran Allah kepada manusia dilakukan melalui dua cara: Pertama secara langsung melalui wahyu yang disampaikan kepada Nabi dan Rasul. Kedua, melalui fitrah yang ditanamkan pada jiwa manusia untuk selalu berkeinginan menyampaikan dan mencari kebenaran. Pengajaran yang pertama merupakan informasi yang dapat diakses manusia melalui ajaran agama, sedangkan pengajaran yang kedua merupakan konfirmasi yang diusahakan manusia melalui eksplorasi terhadap fenomena alam. Baik pengajaran berupa informasi maupun konfirmasi, keduanya merupakan proses pencarian kebenaran yang saling melengkapi untuk menuju kebahagiaan hidup di dunia dan akhirat.

Untuk itulah, maka Allah mengutus Rasul sebagai pendidik yang dalam Alquran disebutkan bertugas sebagai penyampai informasi Tuhan (yatlū 'alaihim àyatih), menyucikan yang berarti mendidik (yuzakkīhim) dan mengajar yang tidak lain menanamkan pengetahuan (yuallimuhum) baik yang berkaitan dengan alam fisika maupun metafisika. Tujuan pendidikan Islam (tarbiyyah) tidak hanya bersifat immanen, tetapi juga transenden. Sebab target yang ditetapkannya adalah melahirkan kesempurnaan manusia agar tercipta mahluk dwidimensi dalam satu keseimbangan, dunia-akhirat, atau ilmu dan iman.

Dalam pendidikan Islam, sasaran yang ingin dicapai adalah melakukan pengaturan dan pembinaan atas segenap aspek potensial manusia agar mencapai kesempurnaan. ${ }^{19} \mathrm{Di}$

19 Kamrani Buseri menyebut pendidikan sebagai upaya untuk memanusiakan manusia, terkait dengan nilai-nilai mengenai manusia itu sendiri yakni apa itu manusia, apa tujuan dari penciptaan manusia, bagaimana manusia yang ideal, bagaimana hubungan 
sisi lain, manusia sebagai mahluk multi dimensi memiliki banyak aspek potensial dari mulai aspek material (jasmani), hingga immaterial (akal dan jiwa). Untuk itulah, maka Allah mengutus Rasul sebagai pendidik yang dalam Alquran disebutkan bertugas sebagai penyampai informasi Tuhan, menyucikan yang berarti mendidik (yuzakkihim) dan mengajar yang tidak lain menanamkan pengetahuan (yu'allimuhum) baik yang berkaitan dengan alam fisika maupun metafisika.

Tujuan pendidikan Islam (tarbiyyah) tidak hanya bersifat immanen, tetapi juga transenden. Sebab target yang ditetapkannya adalah melahirkan kesempurnaan manusia agar tercipta mahlukdwidimensi dalam satu keseimbangan, dunia-akhirat, atau ilmu dan iman. Karena tujuan itu, maka pendidikan Islam menjadikan pemahaman akan kitab suci sebagai salah satu syarat mutlak dalam proses pelaksanaannya. Hal demikian dikarenakan target menciptakan manusia dengan keilmuan dan keimanan yang mantap tidak akan dapat diwujudkan hanya sebatas melalui pengetahuan kognitif yang relatif. Lebih dari itu, kebenaran pengetahuan kognitif harus dikonfirmasikan kepada pengetahuan akan informasi transenden yang mutlak dan absolut. Pengetahuan transenden yang dimaksud adalah pengetahuan akan pesan-pesan kitab suci Alquran, dan pengetahuan tersebut dinamakan tafsir.

Kebutuhan pengetahuan akan kitab suci (tafsir) dalam ilmu pendidikan didasarkan pada aspek-aspek berikut.

1. Tafsir sebagai basis keimanan yang merupakan pengetahuan tertinggi nilainya, dan terdasar kedudukannya dalam susunan pengetahuan manusia sebelum pengetahuan keilmuan yang lain.

2. Tafsir sebagai konfirmasi terhadap kebenaran yang diungkap dalam pengetahuan eksploratif. Artinya pengetahuan

antar manusia, manusia dengan alam semesta, serta bagaimana hubungannya dengan sang pencipta. Lihat Kamrani Buseri, ReinventingPendidikan Islam: Mengagas kembali pendidikan Islam yang lebih baik, cet. Ke-1, (Banjarmasin: Antasari Press, 2010),7. keimanan (informatif) dalam pendidikan Islam dan pengetahuan ekploratif harus saling menguatkan dan membenarkan.

3. Tafsir berfungsi sebagai pelengkap dan penyempurna akan pengetahuan eksploratif yang belum tuntas. Artinya tafsir harus dapat memberi penjelasan tentang fenomena-fenomena yang tidak dapat dijelaskan oleh ilmu pengetahuan eksploratif.

4. Tafsir berfungsi sebagai pengisi nilai (value filler) terhadap pengetahuan eksploratif. Artinya tafsir dimaksudkan sebagai pengetahuan yang dapat mewarnai pengetahuan ekspolaratif agar tidak bebas nilai melalui penanaman nilai-nilai transenden dan etika/moral.

5. Tafsir berfungsi sebagai jembatan yang menghubungkan pesan-pesan ketuhanan agar dapat ditangkap oleh manusia. Dengan kata lain, tafsir merupakan sarana untuk memberikan kesan membumi (indegenous) terhadap pesan-pesan Ilahi yang bersifat suci dan transenden.

6. Tafsir dalam wacana ilmiah yang konstruktif, adalah merupakan lembaga ilmiah yang sudah diterima oleh mayoritas kelompok sesuai dengan corak dan versi masing-masing. Sebagai konsekuensi logisnya akan muncul berbagai polaritas dan pluralitas pendekatan sesuai dengan kecenderungan yang dapat dipandang sebagai bias subyektifitas mufassirnya. Oleh karena itu, dalam dunia Islam didapati tafsir yang bermacam corak, hal ini tentu karena berdasarkan displin ilmu dan subjektifitasnya masing-masing, tidak terkecuali para ahli pendidikan dengan tafsir tarbawinya. ${ }^{20}$

\section{SIMPULAN}

Istilah tafsir telah lazim digunakan untuk memahami Alquran dengan berbagai corak dan jenisnya. Namun setelah sekian lama ilmu dan metode tersebut digunakan dan telah menghasilkan berbagai karya, ternyata masih terfokus pada corak dan ragam tertentu,

20 Ahmad Munir, Tafsir Tarbawi: Mengungkap Pesan Al-Qur'an Tentang Pendidikan,10. 
seperti bahasa, hukum, tasawuf dan lain lain. Dalam dunia pendidikan Islam, tafsir tidak pernah luput dari pengajarannya. Namun ada pertanyaan mendasar, mengapa dalam pendidikan Islam yang mengajarkan tafsir tidak ada yang membahas tafsir Alquran berbasis pada konstruks teori pendidikan.Dari pertanyaan ini, muncul tawaran pendekatan dalam memahami Alquran dengan menggunakan pendekatan pendidikan yang diijtihadkan namanya dengan tafsir tarbawi.

Hal itu dimaksudkan agar para mahasiswa mampu mendekati dan memahami Alquran melalui sudut pandang pendidikan (education perspctive), baik secara teoretik maupun praktik, yang berhubungan dengan kependidikan, melalui kajian kritis terhadap tafsir ayat-ayat dengan metodologi dan pendekatan tafsir tarbawi hingga mampu mengambil simpulan serta mengaplikasikannya dalam praktik pendidikan nyata.

\section{DAFTAR PUSTAKA}

Al-Ashfahānī, al-Raghīb.Mu'jam Mufradāt Alfradat Alfazdal-Qur'ān. Beirut: Dar alFikr, t.t.

Al-Munawar, Said Agil.Alquran Membangun Tradisi Kesalehan Hakiki. Jakarta: Ciputat Press, 2003.

Al-Qaththān, Mannā'.Mabāhis fí 'Ulūmul alQur'ān. Kairo: Maktabah Wahbah, 2004.

Bukhārī,Imām.Shahīh al-Bukhārí, Juz I. Beirut: Dār al-Kutub al-'Ilmiyah, 1992.

Buseri, Kamrani. Reinventing Pendidikan Islam:Mengagas kembali pendidikan Islam yang lebih baik. Banjarmasin: Antasari Press, 2010.

Jalāl, Abdul Fattāh.Min al-Ushūl alTarbawiyyah fï al-Islām, diterjemahkan oleh Herry Noer Ali dengan judul AsasAsas Pendidikan Islam.Cet.1. Bandung: CV.Dipenogoro, 1988.

Ma'luf,Louis. Al-Munjid fĩ al-Lughah wa al'Alām. Cet. XXVII. Beirut: Dār alMasyriq, 1984.

Majid, Nurkholis. Islam Doktrin dan Peradaban: sebuah telaah kritis tentang masalah keimanan, kemanusiaan dan
kemoderenan.Cet. 2.Jakarta: Yayasan Wakaf Paramadina, 1992.

Al-Dzahabi, Muhammad Husein.al-Tafsir wa al-Mufassirūun, Juz I.Mesir: Dār al-Maktūb al-Haditsah, 1976.

Munir, Ahmad.Tafsir Tarbawi: Mengungkap Pesan al-Qur'an Tentang Pendidikan. Yogyakarta; Teras; 2008.

al-Nahlāwí, Abdurrahmn.Ushūl al-Tarbiyyah al-Islāmiyyah wa Asālibihā fỉ al-Baiti wa Madrasati wal Mujtama', cet. 1. Beirut; Dār al-Fikr, 1979.

Nata, Abuddin.Al-Qur'an dan Hadits: Dirasah Islamiyah I.Jakarta: Rajawali Pers, 1993.

Tafsir Ayat-ayat Pendidikan: Tafsir Al-Ayat Al-Tarbawiy. Jakarta: PT Rajagrafindo Persado, 2010.

Al-Qāsimí,Muhammad Jamāluddin. Tafsir Mahāsin al-Ta’wīl.Cet. II. Beirut: Dār alFikr, 1978.

Qutub,Sayyid. Tafsir FỉDhilāl al-Qur'ān. Jilid IV. Juz. XV. Cet. XVII.Al-Qāhirah: Dār alSyurq, 1992.

Al-Rāzi,Imām Fakhruddin. Tafsìr al-Kabỉr, Jilid X. Juz XX. Cet. I. Beirut: Dār alKutub al-'Ilmiyah, 1990.

Al-Shiddiqy, Teungku Muhammad Hasbi, dkk.Sejarah dan Pengantar Ilmu Alquran Dan Tafsir. Semarang: PT. Pustaka Rizki Putera, 1999.

Shihab, M. Quraish.Membumikan Alquran: Fungsi dan Peran Wahyu dalam Kehidupan Masyarakat.Bandung: PT. Mizan Pustaka, 2009.

Tim Penyusun.Ensiklopedia Alquran: Kajian Kosa Kata.Ed. Sahabuddin. Jakarta: Lentera Hati, 2007.

Zayd,Nashr Hamid Abu.MetodeTafsir Kesasteraan atas al-Qur'an.Yogyakarta: Bina Media, 2005. 